\title{
Catalytic Ozonation Using Metal Catalyst Supported on NaY Zeolite
}

\author{
Lan $\mathrm{CHEN}^{\mathrm{a}}$, Yuheng QUAN ${ }^{\mathrm{b}}$ \\ Department of Environment Science \& Engineering, North China Electric Power University, \\ Baoding, 071003, China \\ aemail, zhedayuquan@126.com; bemail, quanyuheng@126.com
}

Keywords: Degradation, Catalytic ozonation, Catalyst

Abstract. In order to enhance the degradation ability of ozonation process, catalyst used in catalytic ozonation was studied in this paper. $\mathrm{NaY}$ zeolite was selected as the carrier of catalyst. Catalysts prepared with different conditions were added in reaction solution to find the catalytic ability of catalyst on dicamba ozonation. The experimental results show that both pure carrier and catalyst have catalytic effect on ozonation. And the catalytic ability of catalyst is more significant. Different calcination temperatures can change the acidity, crystal shape and surface morphology of catalyst, therefore affect the activity of catalyst in catalytic ozonation. With the increase of calcination temperature, the catalytic ability of catalyst decreases. Different metal kinds have different catalytic ability on ozonation. Among these metals, $\mathrm{Ni}$ and $\mathrm{Cu}$ have the best catalytic performance, and $\mathrm{Pb}$ has the poorest catalytic performance, but all metals catalysts have good catalytic capacity.

\section{Introduction}

Recently, pesticides pollution has aroused more and more interest. It can endanger the aquatic ecosystems and soil ecosystems, and therefore threatens human health through the food chain. Dicamba (3,6-dichloro-2-methoxybenzoic acid), one of the chlorinated herbicides, is used to control broadleaf weeds in corn field, wheat field or used for lawn maintenance. Dicamba contamination has occasionally been found in surface water and ground water [1]. Dicamba is harmful to environment and ecosystem [2, 3]. Therefore, the control of dicamba pollution has been paid more and more attention. Maya-Treviño et al. investigated the degradation effeciency of dicamba and 2,4-D herbicides using simulated solar light with $\mathrm{ZnO}-\mathrm{Fe}_{2} \mathrm{O}_{3}$ catalyst [4]. Chu et al. found that the direct photolysis and the photocatalytic process can effectively degrade dicamba in $\mathrm{TiO}_{2}$ suspensions with and without the use of $\mathrm{H}_{2} \mathrm{O}_{2}$ [5].

Advanced oxidation processes (AOPs) have high effeciency in the yield of environment control and treatment. Among them, ozonation has been widely used in disinfection of drinking water and deep treatment of water pollution. Focusing on improvement of ozone decompostion to produce more hydroxyl radicals, a growing number of studies have been reported about combination of ozonation with other techniques such as $\mathrm{O}_{3}$-UV [6], $\mathrm{O}_{3}$-US [7], catalytic ozonation [8] and $\mathrm{O}_{3}-\mathrm{H}_{2} \mathrm{O}_{2}$ [9, 10]. Chen et al. proved that the effectiveness of combined technology of $\mathrm{O}_{3}$ and fly ash $[11,12]$. Zeolite is a crystalline microporous materials. Due to its porous nature and solid acid/base properties, zeolite has been widely used as heterogeneous catalyst or adsorbent in petroleum chemical technology, organic reaction process and environmental remediation [13]. In this paper, $\mathrm{NaY}$ zeolite is selected as carrier to prepare catalyst for catalytic ozonation. The degradation of dicamba using catalytic ozonation was investigated to discuss the catalytic performance of $\mathrm{NaY}$ based catalyst.

\section{Experimental Parts}

The model pollutant used in laboratory was dicamba (Purity $>95 \%$, purchased from Shanghai Yuanye Bio-Technology Co., Ltd.). The reaction solutions were prepared with deionized water without addition of $\mathrm{pH}$ adjusting agents.

Pretreatment process of pure carrier included washing by deionized water, washing by alcohol, and drying at constant temperature $120^{\circ} \mathrm{C}$ and then naturally cooling in dryer. 
Preparation process of catalysts included dipping, drying, calcinating, and cooling. Pure carrier was dipped in metal ion solution and oscillated over $12 \mathrm{~h}$; then dried at constant temperature $120{ }^{\circ} \mathrm{C}$; calcined in muffle furnace for $3 \mathrm{~h}$; and then naturally cooling in dryer.

The catalytic effect of catalyst was judged by the removal performance of dicamba degraded by catalytic ozonation. The ozonation experimental system consisted of a bubble reactor, an ozone generator and some pipes. The ozone generator is purchase from Beijing Tonglin High-tech Technology Co., Ltd. China (3S-A5). A certain amount of catalyst was added into the reaction solution and mixed well before gas introducing. Samples were withdrawn from the reactor periodically, filtered through $0.22 \mu \mathrm{m}$ filter membrane, and then analyzed using HPLC. The concentration of dicamba was determined by HPLC (LC3000, AnHui Wayee Technology Co. Ltd. China). The mobile phase was a mixture of methanol and water (volume ratio of 65:35) ( $\mathrm{pH}$ value was adjusted using phosphoric acid). The flow rate of mobile phase was $1 \mathrm{~mL} \cdot \mathrm{min}^{-1}$. The injection volume was $20 \mu \mathrm{L}$, and the detection wavelength was $230 \mathrm{~nm}$. If no particular mention, the experimental conditions were bellows: the dosage of catalyst was $1.0 \mathrm{~g} \cdot \mathrm{L}^{-1}$; the ozone production of ozone generator was $30 \mathrm{mg} \cdot \mathrm{L}^{-1}$; the gas flow was $1 \mathrm{~L} \cdot \mathrm{min}^{-1}$; the $\mathrm{pH}$ level of solution was initial $\mathrm{pH}$ value without any $\mathrm{pH}$ adjustor; the initial concentration of dicamba was $100 \mathrm{mg} \cdot \mathrm{L}^{-1}$.

\section{Results and Discussion}

Catalytic Effect of Catalyst. In order to investigate the effectiveness of catalysts prepared, several reaction systems are used to degrade dicamba in aqueous solution. These reaction systems include: $\mathrm{O}_{3}$ alone, $\mathrm{O}_{3}-\mathrm{NaY}, \mathrm{O}_{3}$-Catalyst systems. Fig. 1 shows the degradation conditions of dicamba in different reaction systems. In Fig. 1, the catalyst was prepared using $\mathrm{FeSO}_{4}$ solution as dipping solution and with calcination temperature $120^{\circ} \mathrm{C}$ (the catalyst was named as Fe-NaY-catalyst). Fig. 1 (a) is the graph of dimensionless concentration $\left(\mathrm{C} / \mathrm{C}_{0}\right)$ vs. time and Fig. 1 (b) is the graph of $\ln \left(\mathrm{C} / \mathrm{C}_{0}\right)$ vs. time.
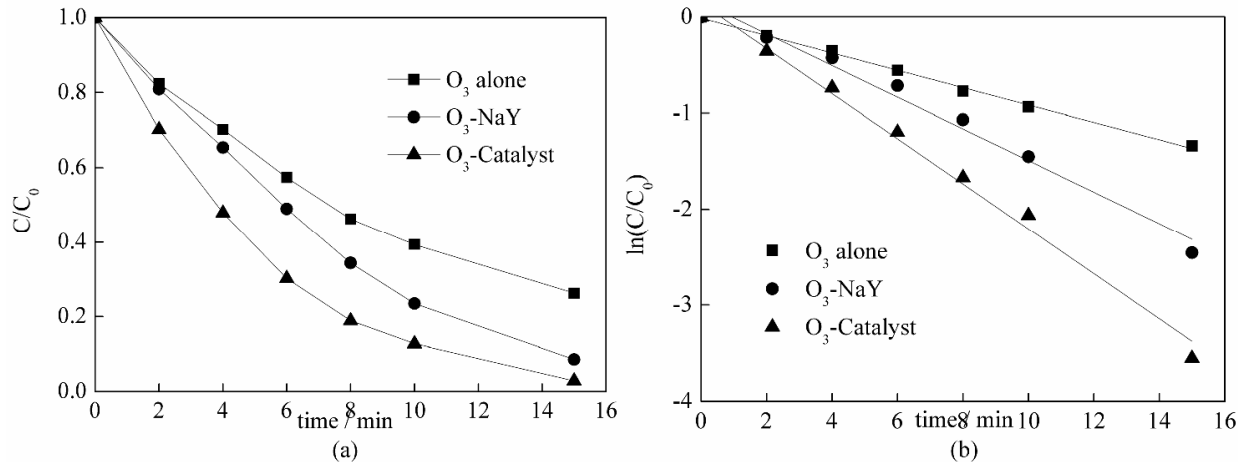

Fig. 1 Comparative experimental of catalytic ozonation

From Fig. 1 (a), it can be seen that the concentration of dicamba decreases gradually alone with the treatment in these systems. The downward trend of concentration follows the order of $\left[\mathrm{O}_{3}\right.$-catalyst system $]>\left[\mathrm{O}_{3}-\mathrm{NaY}\right.$ system $]>\left[\mathrm{O}_{3}\right.$ alone system $]$. It indicates that pure $\mathrm{NaY}$ has a certain catalytic effect on ozonaiton, and the catalytic effect of $\mathrm{Fe}-\mathrm{NaY}$-catalyst is higher. In ozonation process, dicamba can be degraded by the direct oxidation of ozone molecules and the indirect oxidation of hydroxyl radicals. The kinetic of dicamba degradation can be fitted by pseudo-first-order kinetics [11]. Fig. 1 (b) shows that there is a good linear between $\ln \left(\mathrm{C} / \mathrm{C}_{0}\right)$ and time in these systems. The slope of line is the pseudo-first-order rate constant $(k)$. The rate constants in $\mathrm{O}_{3}$ alone system, $\mathrm{O}_{3}-\mathrm{NaY}$ system and $\mathrm{O}_{3}$-catalyst system are calculated as $0.0902,0.1646$ and $0.2347 \mathrm{~min}^{-1}$, respectively. The decreasing tendency of dicamba concentration using carrior/catalyst without $\mathrm{O}_{3}$ is not obvious, which shows that the direct adsorption ability of carrier or catalyst do not work during dicamba degradation. The rate constants in thses conditions are very small and and can be ignored. The enhancing facter $(E)$ of catalyst can be calculated using $k / k_{\mathrm{O} 3}\left(k\right.$ and $k_{\mathrm{O} 3}$ are rate constants of catalytic ozonation and ozonation alone, respectively). $E$ values of carrier and catalyst are 1.83 and 2.60. Hence, the addition of pure $\mathrm{NaY}$ or Fe-NaY-catalyst into reaction solution shows markedly improving on ozonation of dicamba. Zeolite carrier and catalyst have porous, loose structure and acidic properties, which helps organics and ozone 
molecules adsorbing onto the surface of zeolite, and then promotes ozone decomposition to produce hydroxyl radicals and improve the reaction of organic species with active species (hydroxyl radicals and $\mathrm{O}_{3}$ molecule).

Effect of Calcination Temperature of Catalyst. The calcination temperature can affect the catalytic ablity of catalyst. Fig. 2 (a) shows concentration trend of dicamba in catalytic ozonaiton. Fig. 2 (b) shows $\ln \left(\mathrm{C} / \mathrm{C}_{0}\right)$ vs. time to fit the pseudo-first-order kinetic. In Fig. 2, the catalyst was prepared using $\mathrm{FeSO}_{4}$ solution as dipping solution and with different calcination temperature: $120,400,600,800{ }^{\circ} \mathrm{C}$.

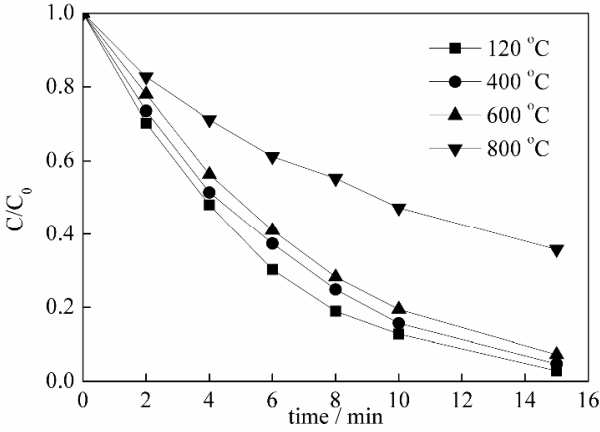

(a)

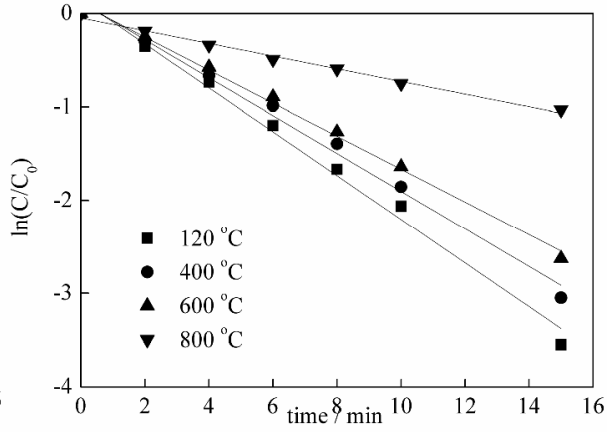

(b)

Fig. 2 Effect of calcination temperature on catalytic performance

From Fig. 2, it is shown that calcination temperature has significantly influence on dicamba degradation efficiency that represents the catalytic ability of different catalyst. In catalytic ozonation process using catalysts prepared with different calcination temperatures, the degradation rate of dicamba decreases with the increase of calcination temperature. Among these catalysts, catalyst (120 $\left.{ }^{\circ} \mathrm{C}\right)$ has the best catalytic activity, catalyst $\left(800{ }^{\circ} \mathrm{C}\right)$ has the worst catalytic activity, and catalyst $\left(600{ }^{\circ} \mathrm{C}\right)$ has relatively good mechanical strength and repeatability. Different calcination temperatures can change the acidity, crystal shape and surface morphology of catalyst. With the increase of calcination temperature, the specific surface area and pore volume decrease, while the average pore size increases, which would reduce the effective diffusion coefficient and inhibit the degradation of dicamba. Excessive high temperature may lead to pore collapse and metal particle agglomeration, which brings to the massive loss of catalyst surface area and pore volume. Hence, the number of active centers of catalyst is lessened, the catalyst activity is reduced. The catalytic ozonation using catalyst prepared in $800{ }^{\circ} \mathrm{C}$ has a relatively low degradation rate, which shows the activity of catalyst is significantly reduced.

Effect of Metal Kinds of Catalyst. Using different metal solutions as dipping solution to prepare catalyst will bring to different catalytic performance on ozonation. Fig. 3 (a) shows concentration trend of dicamba in catalytic ozonation using different metal-catalysts. Fig. 3 (b) shows $\ln \left(\mathrm{C} / \mathrm{C}_{0}\right)$ vs. time. In Fig. 3, the catalyst was prepared using different metal nitrate solutions at same concentration as dipping solution and with calcination temperature $600{ }^{\circ} \mathrm{C}$. These metal nitrate solutions include $\mathrm{NiNO}_{3}$, $\mathrm{Mn}\left(\mathrm{NO}_{3}\right)_{2}, \mathrm{Cu}\left(\mathrm{NO}_{3}\right)_{2}, \mathrm{Zn}\left(\mathrm{NO}_{3}\right)_{2}$ and $\mathrm{Pb}\left(\mathrm{NO}_{3}\right)_{2}$.
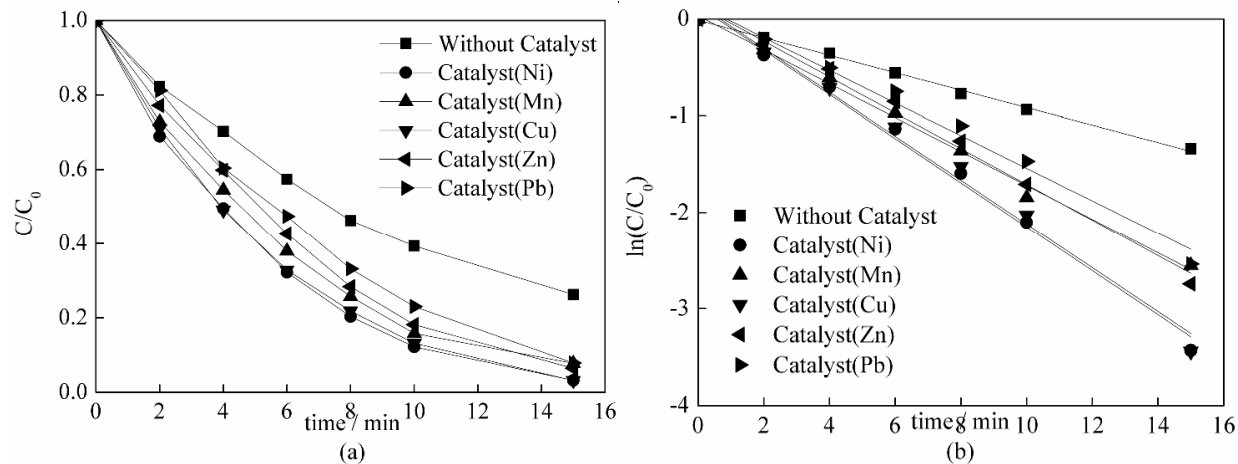

Fig. 3 Effect of metal kinds on catalytic performance

From Fig. 3, metal kinds have different enhancing effect on ozonation. Rate constants of catalytic ozonation using $\mathrm{NaY}$ loaded with $\mathrm{Ni}, \mathrm{Cu}, \mathrm{Zn}, \mathrm{Mn}$ and $\mathrm{Pb}$ are $0.2284,0.2273,0.1852,0.1754$ and $0.1687 \mathrm{~min}^{-1}$, respectively. And corresponding enhancing factors value are 2.53, 2.52, 2.05, 1.94 and 
1.87, respectively. Among these metals, $\mathrm{Ni}$ and $\mathrm{Cu}$ have very similar enhancing factors and have best catalytic performance; $\mathrm{Pb}$ is the least effective catalytic metal but still greatly promote the degradation of dicamba.

\section{Conclusions}

In this study, catalysts prepared with $\mathrm{NaY}$ carrier were used in the catalytic ozonation process with dicamba as model pollutant. The catalytic abiltiy of different catalysts was determined by the degradation efficiency of dicamba. Pure $\mathrm{NaY}$ and Fe-NaY-catalyst both have catalytic effect on ozonation, and the latter is better than the former. The catalytic ability of Fe-NaY-catalyst is significant. During the preparation of catalyst, the calcination temperature has great influence on the catalytic ability of catalyst. With the increase of temperature, the catalytic ability of catalyst decreases. Different temperatures can change the acidity, crystal shape and surface morphology of catalyst, therefore affect the catalyst capacity in catalytic ozonation. Different metal kinds have different enhancing effect on catalytic ozonation. Among these metals, $\mathrm{Ni}$ and $\mathrm{Cu}$ are the best effective catalytic metals and $\mathrm{Pb}$ is the least effective catalytic metal, but all have good catalytic ability on catalytic ozonaiton of dicamba.

\section{Acknowledgements}

This work was financially supported by the Fundamental Research Funds for the Central Universities (No. 2014MS123).

\section{References}

[1] D.B. Donald, A.J. Cessna, E. Sverko, N.E. Glozier: Environ. Health Perspect. Vol. 115(2007), p. 1183-1191.

[2] C.R. de Arcaute, S. Soloneski, M.L. Larramendy: Mutation Research. Vol. 773(2014), p. 1-8.

[3] N.V. González, S. Soloneski, M.L. Larramendy: Journal of Hazardous Materials. Vol. 163(2009), p. 337-343.

[4] M.L. Maya-Treviño, J.L. Guzmán-Mar, L. Hinojosa-Reyes, N.A. Ramos-Delgado, M.I. Maldonado, and A. Hernández-Ramírez: Ceramics International. Vol. 40(2014), p. 8701-8708.

[5] W. Chu, and C.C. Wong: Water Research. Vol. 38(2004), p. 1037-1043.

[6] W. Zhao, Q. Liao, J. Zhang, Y. Yang, J. Dai, D. Zhao: Chemical Engineering Journal. Vol. 171(2011), p. 628-639.

[7] Z. He, L. Lin, S. Song, M. Xia, et al: Separation and Purification Technology. Vol. 62(2008), p. 376-381.

[8] L. Yuan, J. Shen, Z. Chen, Y. Liu: Applied Catalysis B: Environmental. Vol. 117-118(2012), p. 414-419.

[9] L. Chen, Y. Quan: CIESC Journal. Vol.62(2011), p. 2920-2925(in Chinese).

[10] L. Chen, Y. Quan: CIESC Journal, Vol.62(2011), p. 2926-2931(in Chinese).

[11] L. Chen: Influence Factor of Dicamba Degradation Using $\mathrm{O}_{3}$-FA Process in Aqueous Solution. ICEEMA 2015, 2015, 6.

[12] L. Chen, Y.Y. Wang: Degradation of Dicamba in Aqueous Solution Using Ozonation Assisted by Fly Ash. ICEEMA 2015, 2015, 6.

[13] T. Yamamoto, A. Eiadua, S.-I. Kim, T. Ohmori: J. Ind. Eng. Chem. Vol. 13(2007), p. 1142-1148. 